\title{
PREVALENCE OF INCIDENTS OF STREET SEXUAL HARASSMENT AGAINST WOIMEN IN DELHI.
}

KEY WORDS: Sexual harassment, women, patriarchy

\section{Yuvika Bishnoi Student, Ryan International School,Vasant Kunj}

E 1 Sexual harassment is a pressing, though common, social problem. This research paper attempts to understand the occurrence of incidents of sexual harassment as experienced by women in Delhi. Under the broad umbrella of 'sexual harassment' in itself, street sexual harassment can be seen as the most routine; thus, serving as the reason to narrow down the study to street sexual harassment per se. The objective of the study was to find out the reasons, impacts, and forms of street sexual harassment mainly faced by women in Delhi.

\section{INTRODUCTION}

The Australian Human Rights Commission defines sexual harassment as 'an unwelcome sexual advance, unwelcome request for sexual favours or other unwelcome conduct of a sexual nature which makes a person feel offended, humiliated and/or intimidated, where a reasonable person would anticipate that reaction in the circumstances.' (Australian Human Rights Commission,-)

Sexual harassment constitutes a profoundly disturbing picture in women's lives. From workplaces to streets, women have been victims of harassment for centuries, and presentday statistics bring testimony to the statement. Under the broad ambit of sexual harassment, sexual harassment in public places is a serious and majorly prevalent problem. This research paper fixes its lens on street harassment perpetrated against women in India's capital- Delhi. In the union territory, $95 \%$ of women aged 16-49 report feeling unsafe in public spaces. (UN Women, 2013) Women incur significant psychological and physiological stress from sexual harassment. Unjustly, in most cases, the victims, women themselves, are the ones who are blamed and maleperpretrator empathy is considered more or equally important than female-victim empathy. (Bongiorno, Langbroek, Bain, Ting, \& Ryan, 2019) The attitudes of men and society add on to such experiences and behaviours.

This paper will present the causes and consequences of the prevalence of street harassment for our demographicwomen, particularly those living in Delhi.

\section{Problem Identification}

Sexual harassment is really like one big doll holding a number of other small dolls and topics and perspectives hidden on the inside. Touch one and you will uncover the other one and so on. (Busljeta, 2019)

Rightly so, sexual harassment is not about an individual problem, but about 'understanding that at the root of all of these problems is a culture of toxic masculinity, about what it means to be a man'. (McBee, 2017)

Delhi, a state, although considered to be relatively cosmopolitan, modern, and one of the "best to live in India," also faces problems such as overcrowding, tremendous pressure on its infrastructure, and rising crime rates. (Dhillon \& Bakaya, 2014) The city has assessed a reputation of an unsafe city, especially for women.

Street Harassment has been ingrained into big cities for a long time. However, it is not a blanket issue, there are multiple forms of street harassment, and hence, multiple methods of intervention.

Understanding the roots of the problem will assist in focusing on feasible solutions for each problem.
The patriarchal ideology prevalent in India has been historically integrated into culture and thus, upbringing of the later generations. It is the way the world has been organised with regards to gender- superiority of one gender. Beliefs, practices, ideas, education, and behaviours are engraved deep into social practices and institutions. It is this disproportion that fuels trajectories like sexual harassment, rape, domestic violence etc.

Sexual assault isn't simply about a person's sexual desires; it has more to do with the three P's: Patriarchy, Power and Property. A patriarchal society where the power rests with the men, and women are simply considered to be their property, will always shame the woman. (Goel, 2020) It is routine to question the victim; ask them about their clothing, physical location, time of the day, and probable advancements/signals given by them. Out of the total 40 women who were surveyed, $82.5 \%$ reported having experienced sexual harassment. Furthermore, majority of the victims (87\%) reported having experienced/witnessed sexual harassment in their minor years.

In India, male-children are usually not neglected as femalechildren are. For generations, according to the division and allocation of assets, they were received by males due to them being regarded as the "financial support" of the family. Malechildren are coerced into fitting the so-called 'man-box'; not showing any sight of weakness, exerting dominance and control, being the breadwinner, and adhering to rigid and toxic gender roles.

A patriarchal mindset among abusers leads to men venting their frustrations or powering their ego through harassment of women. A report submitted by the Delhi police to the Supreme Court of India revealed that complaints about harassment in public spaces registered a fivefold increase from 154 in 2012 to 793 in 2013. (Mahapatra, 2013) It can be interpreted that the data intensifies with time and so does the need to curb harassment.

\section{METHODS}

\subsection{Study area}

The study was conducted in New Delhi, India

\subsection{Study universe}

The study universe consists of women residing/having resided in Delhi for a considerable period of time, who go outside of their homes on a regular basis for purposes such as schooling, college, or working profession.

\subsection{Inclusion criteria}

Women residing in New Delhi who are from diverse socioeconomic backgrounds, whose daily life include stepping outside of their houses, and are willing to participate in the study and give assent were included. 17 participants were students studying in school. The remaining were either pursuing higher studies or working. 


\subsection{EXCLUSION CRITERIA}

Other genders and uncooperative women were excluded from this study.

\subsection{Pretesting of the questionnaire}

The designed questionnaire was pretested on $12.5 \%$ of the total sample. Relevant modifications were made in the survey forms to overcome the difficulties faced during pretesting.

\subsection{Limitations}

Keeping in mind the pandemic circumstances, the survey was conducted in an online mode with the questionnaires being filled through the internet. Therefore, the survey participants have only been people with a suitable internet connection, thus, leaving out women from certain poor socio-economic backgrounds.

\subsection{Ethical consideration}

The questionnaire was made taking the sensitivity of the issue into consideration. The survey participants were assured about absolute confidentiality of their responses, and the option of preserving anonymity was also given.

\section{RESULTS}

Based on the findings of the study, it can be evidently seen that incidents of street sexual harassment are indeed highly prevalent in Delhi and affect the lives of the women living in the city. Out of the total 40 women who were surveyed, $82.5 \%$ reported having experienced sexual harassment. Majority of the victims $(87 \%)$ reported having experienced/witnessed sexual harassment in their minor years. The forms range from staring $(80 \%)$, inappropriate comments $(42.5 \%)$, invasion of private space $(42.5 \%)$, whistling/animal noises $(40 \%)$, following/stalking (30\%), groping/grabbing (22.5\%), public exposure (10\%); only $12.5 \%$ participants reported not having experienced any of the aforementioned forms of harassment. It has been found out that ignoring (70\%) and moving away $(65 \%)$ are the most common responses of the participants on experiencing harassment. Only $17.5 \%$ called out their perpetrator, and merely $5 \%$ went to the extent of registering a formal complaint. In most of the experiences ( $80 \%)$, no one intervened to help the victim. However, when intervention did occur, it bettered the situation only $28.6 \%$ of the times. Statistically significant association was found in the participants between 'feeling better' after having shared their harassment stories. Most common impacts of having experienced sexual harassment include anxiety, depression and PTSD $(40 \%)$, reduced quality of life $(20 \%)$, limited mobility (20\%), and skipping school/work (15\%). Majority of the respondents $(70 \%)$ believe that the location where they are at or the time of the day does affect their vulnerability. The most common physical location where sexual harassment occurs can be seen as the street $(62.5 \%)$, with others being big gatherings (35\%), isolated areas (32.5\%), school/ workplace $(22.5 \%)$, and restaurants/cafes (15\%). Majority of the respondents $(80 \%)$ are more conscious about stepping out during the night and/or about their outfit. Same is the case with choosing to use public transport; $80 \%$ of the participants don't feel safe in doing so. As regards the reasons behind occurrence of incidents of sexual harassment, most participants $(87.5 \%)$ believe that the major reasons are taboos around sex and conservative mindset, and lack of education and awareness. Other reasons such as male dominated ratios and leadership (77.5\%), inefficient laws $(65 \%)$, lack of police accountability, and an organisational climate that tolerates this $(57.5 \%)$, and underconfidence in women (30\%), are also popularly believed.

Table 1: Consolidated responses of the survey questions

\begin{tabular}{|l|l|l|}
\hline QUESTIONS & YES & NO \\
\hline $\begin{array}{l}\text { Have you ever experienced sexual } \\
\text { harassment? }\end{array}$ & $82.5 \%$ & $17.5 \%$ \\
\hline Did you share your story with anyone? & $62.5 \%$ & $37.5 \%$ \\
\hline
\end{tabular}

www.worldwidejournals.com \begin{tabular}{|l|l|l|}
\hline Did the experience affect your quality of & $47.5 \%$ & $52.5 \%$ \\
\hline
\end{tabular} life?

\begin{tabular}{|l|l|l|}
\hline Did someone intervene? & $20 \%$ & $80 \%$ \\
\hline
\end{tabular}

\begin{tabular}{|l|l|l|}
\hline Do you think the location where you're at & $70 \%$ & $30 \%$
\end{tabular} or the time of the day affects your vulnerability?

Are you more conscious about stepping out during the night and/or about your outfit?

Do you feel safe while using public transport, in the context of sexual harassment?

Figure 1: At what age did you first witness or experience harassment?

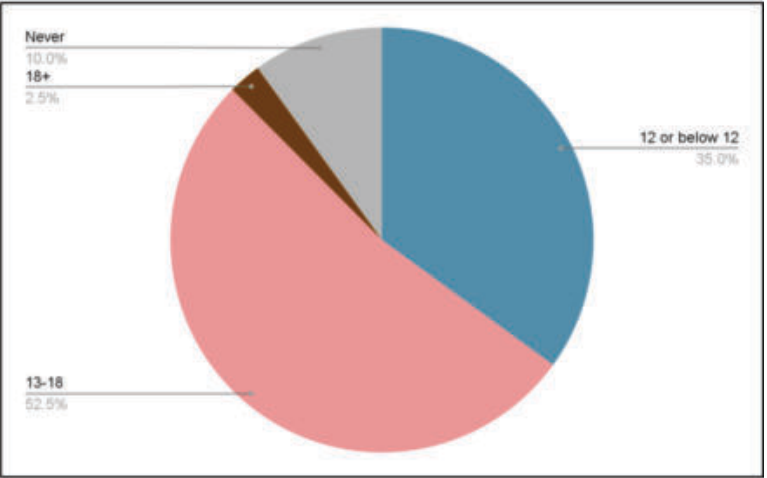

Figure 2:Where have you experienced sexual harassment?

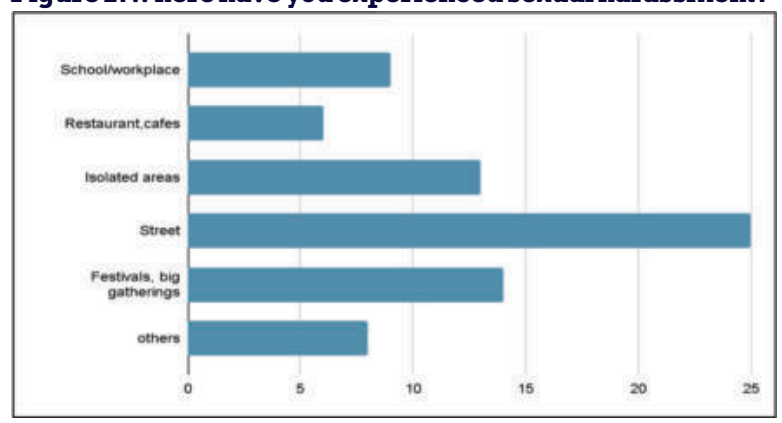

Figure 3: What forms of sexual harassment have you experienced?

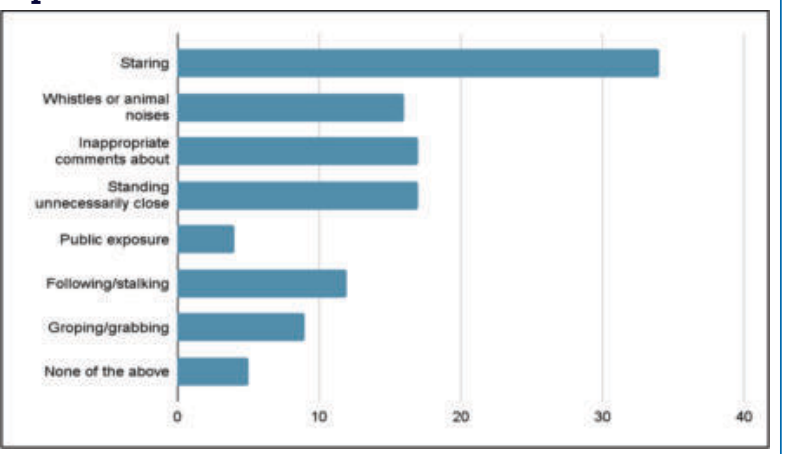

Figure 4: How did you react to the incident?

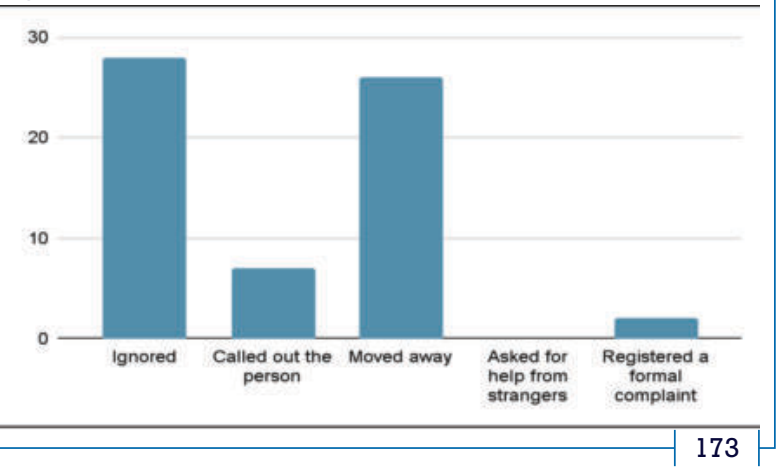


Figure 5: What according to you are the impacts of sexual harassment?

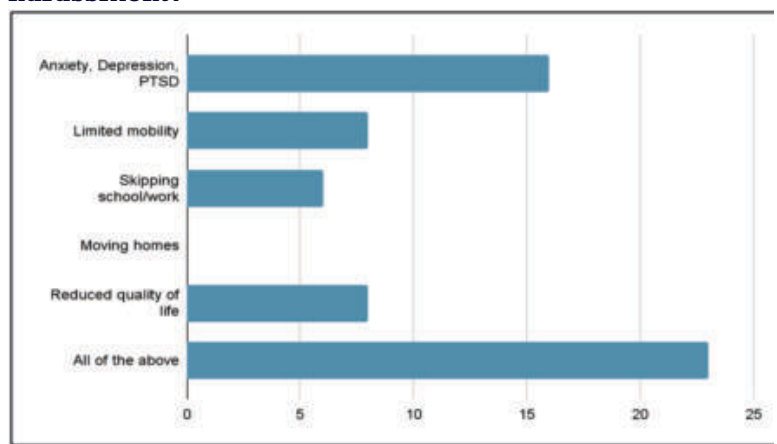

\section{CONCLUSION}

Profound issues stemming from globalization and traditional cultural tendencies have created unfavorable settings for women in public spaces. (Nalla, 2020) The study clearly concludes that sexual harassment, is indeed, a significantly prevalent problem in Delhi. The constant possibility of being harassed in public places seems to control different aspects of the women's lives, including their choice of using public transport, choice of clothing, time of the day at which they can step out etc. Out of the places reported as areas where sexual harassment usually occurs, streets have been found out as the most common. The findings from the study entail the need to treat street harassment by spreading awareness about the topic, educating both men and women on how to deal with harassment, and/or creating an atmosphere of safety. Most importantly, there is a major need for police accountability and the presence of efficient laws. In order to successfully combat street harassment, it is imperative to utilize the comprehensive legislation and attempt to ensure that the ground reality of its implementation is effective.

\section{REFERENCES}

1. Australian Human Rights Commission. (-). Sexual Harassment in Workplace Legal Definition. Retrieved June 19, 2021, from humanrights.gov.au: https://humanrights.gov.au/our-work/sexual-harassment-workplace-legaldefinition-sexual-harassment

2. Bongiorno, R., Langbroek, C., Bain, P. G., Ting, M., \& Ryan, M. K. (2019, August 18). Why Women Are Blamed for Being Sexually Harassed: The Effects of Empathy for Female Victims and Male Perpetrators. Retrieved June 26, 2021 , from journals.sagepub.com: https:// journals. sagepub. com/ doi/ full/ 10. $1177 / 0361684319868730$

3. Busljeta, v. (2019, November 13). On Sexual Harassment, Patriarchy and Roles we play. Retrieved June 2, 2021 , from nn: https:// www. my news desk. com/ non violenceproject/blog_posts/on-sexual-harassment-patriarchy-androles-we-play-87953

4. Dhillon, M. \& Bakaya, S. (2014). Street Harassment: A Qualitative Study of the Experiences of Young Women in Delhi. SAGE Open, 2014(July-September 2014), 3. Retrieved from sgo.sagepub.com: https:// journals. sagepub. com/doi/pdf/10.1177/2158244014543786

5. Goel, P. (2020, April 18). Patriarchy, Power and Property have normalised sexual assault in India. Retrieved June 2, 2021, from The Breakthrough Voice: https://inbreakthrough.org/power-property-rape-culture/

6. Mahapatra, D. (2013, October 31). The Times Of India. Retrieved from www.timesofindia.indiatimes.com: http://timesofindia. indiatimes. com/ city/ delhi/Crimes-against-women-up-in-2013/articleshow/24953275.cms

7. McBee,T.P. (2017, october 15). The myth of the "good"man. Retrieved june 26, 2021, from Quartz: https://qz.com/1 100206/how-many-bad-men-do-will-ittake-for-us-to-start-talking-about-how-to-save-our-sons/

8. Nalla, M. (2020), research gate. Retrieved from www.researchgate.net: https:// www. researchgate. net/ publication/ 342753845 Sexual harassment in public spaces_in_India_Victimization_and_offending_patterns

9. Stop Street Harassment. (2011). Statistics - The Prevalence of Street Harassment. Retrieved June 18, 2021, from https://stopstreetharassment.org/: https:// stopstreetharassment.org/resources/statistics/statistics-academic-studies/

10. UN Women. (2013, February 20). UNWomen supported survey in Delhi shows 95 per cent of women and girls feel unsafe in public spaces. Retrieved June 19, 2021, from https://www.unwomen.org/: https:// www. unwomen. org/ en/ news/stories/2013/2/un-women-supported-survey-in-delhi 